\title{
Oral Intraepithelial Neoplasia
}

National Cancer Institute

\section{Source}

National Cancer Institute. Oral Intraepithelial Neoplasia. NCI Thesaurus. Code C133192.

A precancerous neoplastic process affecting the oral mucosa. It is characterized by the presence of dysplasia in the mucosal epithelium. 